\title{
Generation of stress-strain state in combined strip pile foundation beds through pressing of soil
}

\author{
Maxim Stepanov ${ }^{1, *}$, Roman Melnikov ${ }^{1}$, Juriy Zazulya ${ }^{1}$ and Oleg Ashihmin ${ }^{1}$ \\ ${ }^{1}$ Industrial University of Tyumen, 625001, Volodarskogo str., 38, Tyumen, Russia
}

\begin{abstract}
When erecting high-rise buildings, weak underlying soils cause a number of problems in design and construction. In order to ensure the required non-exceedance of the ultimate limit settlements, the combined strip pile foundation has been developed allowing the soil bed to be prestressed. This is achieved by injection of pressurized mortar (pressing). The paper analyzes the effect of soil pre-stressing followed by pressing of foundation with the cement mortar, as applied to existing structures using the Plaxis 3D software package in conditions of volume deformation and the Hardening Soil Model. Variable order of foundation pressing allows the required parameters of soil bed to be achieved in plan and depth, thus improving interaction with the foundation and superstructure.
\end{abstract}

\section{Introduction}

When erecting different structures, weak underlying soils cause a number of problems in design and construction [1]. To ensure the required non-exceedance of the ultimate limit settlements is challenging under the pressure ranging from 200 to $450 \mathrm{kPa}$ which acts upon the bed in soil conditions composed of alluvial soils with relatively low strength and deformation characteristics. Slab foundations are not applicable due to extra calculated settlements; pile foundations, i.e. driven piles up to $12 \mathrm{~m}$ in depth, are not applicable because of their low bearing capacity, and composite precast piles and drilling technologies are resource-demanding and expensive [2-4].

\section{Combined strip pile foundations}

In order to ensure the required non-exceedance of the ultimate limit settlements, it is offered to use the combined strip pile foundations (CSPF) with possible pre-stressing of soil bed by its pressing (Fig. 1) [5].

\footnotetext{
${ }^{*}$ Corresponding author: maxim_stepanov@inbox.ru
} 


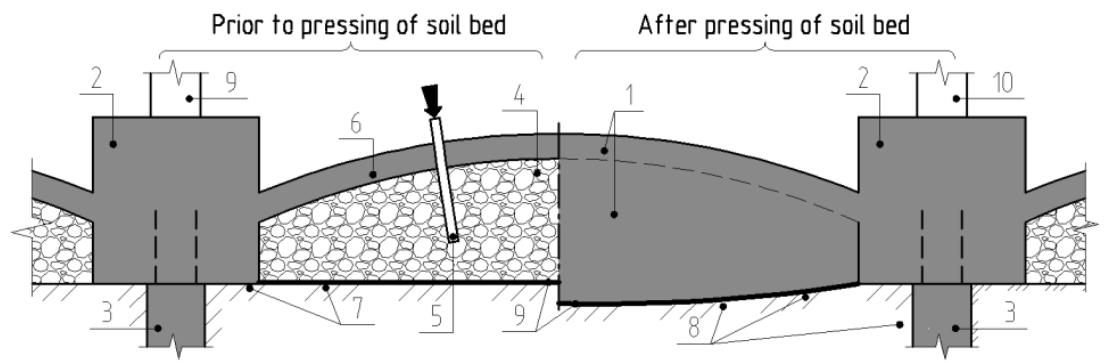

Fig. 1. CSPF prior to and after pressing: 1 - slab of variable stiffness; 2 - strip frames; 3 - piles; 4 mineral footing; 5 - injectors; 6 - shell; 7 - soil bed; 8 - totally enclosed elastic membrane; 9 compacted soil bed; 10 - walls and columns.

CSPF is composed of the slabs of variable stiffness limited by the cross-shaped frames incorporating bearing piles. The foundation is a technologically transformed system in which the reinforced shell of the positive or zero Gaussian curvature is stressed with mortar; it is placed along a curvilinear surface of an artificial footing made of crushed stone or other mineral material; after hardening of the injected mortar it is transformed into a slab of variable stiffness.

This type of foundations significantly differs from the well-known combined ones which are now widely used worldwide and studied by many domestic and foreign researchers [6-12]. The principal differences of the proposed foundations from the combined pile-slab foundations are as follows:

- Piles eliminate the lack of soil bed stiffness and are not located under the entire area of the building with certain spacing in two directions, but directly under the force lines of loading (load-bearing walls, columns).

- The slab of variable stiffness is less resource-demanding, and location of the entire working reinforcement through the main tensile stresses makes it possible to take the bending moments and shear forces effectively after the external (operational) loads are applied on the foundation.

- Each member of the foundation is involved in structural performance at an early stage of constructing a building or structure.

- The structural properties of soil stressed with pressing can be significantly improved in the foundation, and soil compressibility is reduced in the active layer.

- The soil bed stressed with pressing allows additional pressing to be created by lateral pressure of the upper part of piles resulting in their load-bearing capacity increase.

- During the first and (possible) subsequent cycles of loading and unloading with pressing, the soil accumulates residual deformations and residual stresses (lateral pressure) affecting the stress-strain state of the soil bed directly under static loading of the foundation. In the initial stages of operation load the soil behaves in accordance with the secondary loading module $\mathrm{E}_{\mathrm{e}}$ in the active layer $[5,13]$.

- Recovery due to "foundation - soil bed" contact layer pressing, elimination of destructurization arising due to weather, groundwater and hydrodynamic pressure impacts on the soil bed, dynamic impacts of mechanisms and errors of builders during earth work.

- Elimination of deformations caused by freezing and subsequent thawing of the soil bed in constructing foundations of buildings or structures in cold seasons.

- An anti-filtration membrane is formed due to the use of the highly water-resistant hydraulic mortar as an injection [14]. 


\section{Influence of soil bed pressing on stress-strain state development}

Soil bed pressing has a significant influence on its stress-strain state development. Variable parameters, such as pressing pressure, order of foundation pressing, staging of procedures during construction or operation of a structure make it possible to achieve the required parameters of the soil bed in plan and depth, thus improving interaction with the foundation or superstructure.

In order to analyze the influence of the spread of soil pre-stressing on the existing structures, the problem of continuous CSPF modeling was considered using Plaxis 3D software package in conditions of volume deformation and the Hardening Soil Model [15] (Fig. 2). The model parameters are given in Table 1.

Table 1. Hardening Soil Model parameters.

\begin{tabular}{|c|c|c|c|}
\hline Symbol & Name & Value & UOM \\
\hline $\mathrm{E}_{50}^{\mathrm{ref}}$ & $\begin{array}{l}\text { Chord modulus for } 50 \% \text { values of a deviator, obtained } \\
\text { from triaxial tests }\end{array}$ & 3875 & $\mathrm{kN} / \mathrm{m}^{2}$ \\
\hline $\mathrm{E}_{\text {oed }}^{\mathrm{ref}}$ & $\begin{array}{l}\text { Tangent modulus of elasticity, obtained from compressive } \\
\text { tests }\end{array}$ & 3100 & $\mathrm{kN} / \mathrm{m}^{2}$ \\
\hline $\mathrm{E}_{\mathrm{ur}}^{\mathrm{ref}}$ & $\begin{array}{l}\text { Modulus of elasticity in unloading - repeated loading, } \\
\text { obtained from compressive tests }\end{array}$ & 23250 & $\mathrm{kN} / \mathrm{m}^{2}$ \\
\hline$v_{\text {ur }}$ & $\begin{array}{l}\text { Poisson ration in unloading - repeated loading, by default } \\
v_{\mathrm{ur}}=0.2\end{array}$ & 0.2 & - \\
\hline m(power) & $\begin{array}{l}\text { Exponent of power to describe the effect of confining } \\
\text { pressure on the modulus of elasticity; it is obtained from } \\
\text { compressive tests. }\end{array}$ & 0.9 & - \\
\hline $\mathrm{K}_{0}$ & $\begin{array}{l}\text { Coefficient } \quad \text { of } \quad \text { earth } \\
\mathrm{K}_{0}=\sigma_{\mathrm{xx}}^{\prime} / \sigma_{\mathrm{yy}}^{\prime} \text { in consolidation, } \mathrm{K}_{0}^{\mathrm{NC}}=1-\sin \varphi\end{array}$ & 0.724 & - \\
\hline $\mathrm{p}^{\mathrm{ref}}$ & Reference level of stresses, by default $\mathrm{p}^{\mathrm{ref}}=100$ & 100 & $\mathrm{kN} / \mathrm{m}^{2}$ \\
\hline c & Effective cohesion, obtained from triaxial tests & 41 & $\mathrm{kN} / \mathrm{m}^{2}$ \\
\hline$\varphi($ phi) & $\begin{array}{l}\text { Effective angle of internal friction, obtained from triaxial } \\
\text { tests }\end{array}$ & 16 & degrees \\
\hline$\Psi(\mathrm{psi})$ & $\begin{array}{l}\text { Effective angle of dilatancy, obtained from triaxial tests, } \\
\text { usually } \psi=\varphi-30^{\circ}\end{array}$ & - & degrees \\
\hline
\end{tabular}

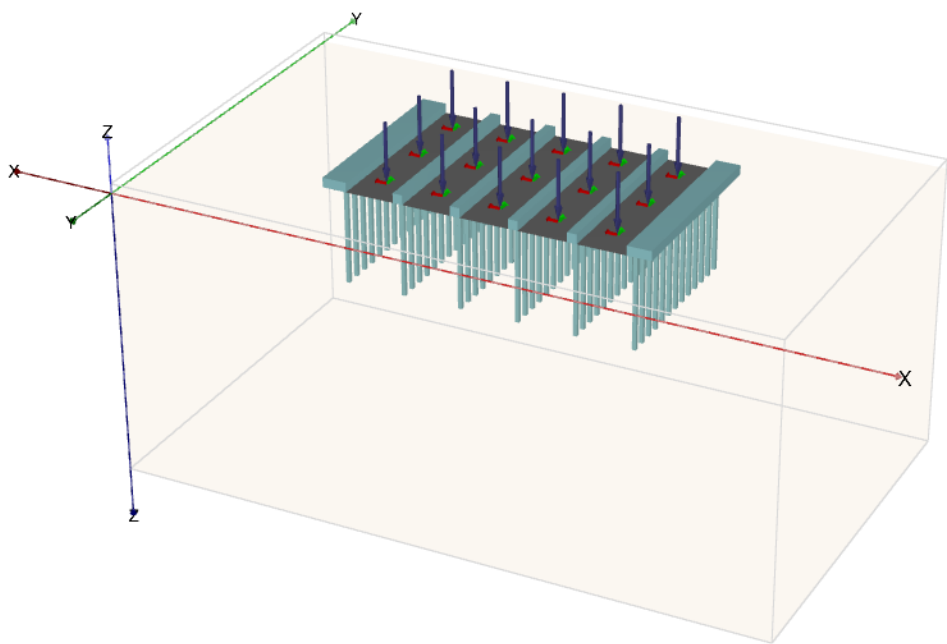

Fig. 2. Diagram of continuous CSPF soil pre-stressing. 
The diagram illustrates five crimped bays of soil bed located between the strips of pile foundations. The diagram shows edge bays (further - bay No 1 and bay No 5), middle bays (further - bay No 2 and bay No 4) and the central bay (further - bay No 3 ).

The foundation is composed of six pile strip foundations; the distance between the axes is $6 \mathrm{~m}$. The piles are made of square section $-300 \times 300 \mathrm{~mm}, 1=12 \mathrm{~m}$ in length; the distance between the piles is $1 \mathrm{~m}$ in a strip. The load, $100 \mathrm{kPa}$ in intensity, representing the process of soil bed pressing, is applied to the whole width of the bay and is uniformly distributed over the area.

It should be noted that when pressing each subsequent bay, the uniformly distributed load applied to the soil bed in the previous bay was eliminated.

Four different patterns $(\mathrm{P})$ for soil pre-stressing have been considered:

P1 - Pre-stressing of soil bed is carried out from the edges to the center, allowing further compression of the central bay to be done. This pattern makes it difficult to spread the deformations of soil bed beyond the foundation; stresses are concentrated in the soil bed between the central pile strip foundations (in the zone where the soil bed is most loaded in the process of construction).

Pattern: No $1+$ No $5 \rightarrow$ No $2+$ No $4 \rightarrow$ No 3 (Fig. 3a; Fig. 4a).

P2 - Pre-stressing of soil bed is carried out from the center to the edges of the foundation. This pattern makes it possible to squeeze water from the soil beyond the construction footprint in case of water-saturated soils.

Pattern: No $3 \rightarrow$ No $2+$ No $4 \rightarrow$ No $1+$ No 5 (Fig. 3b; Fig. 4b).

P3 - Pre-stressing of soil bed is carried out from the middle bays. This pattern makes it possible to distribute the stresses appearing in the soil during pressing more evenly; this may be useful in case of a uniformly distributed load on the foundation from a building or structure.

Pattern: No $2+$ No $4 \rightarrow$ No $3 \rightarrow$ No $1+$ No 5 (Fig.3c; Fig.4c).

P4 - Pre-stressing of soil bed is based on tangent pile walls; in here, longitudinal pressing is carried out within one bay with the movement from the center to the edges, or vice versa.

Pattern: No $1+$ No $5 \rightarrow$ No $3 \rightarrow$ No $2+$ No 4 (Fig. 3d; Fig. 4d).

\section{Numerical simulation results}

a)

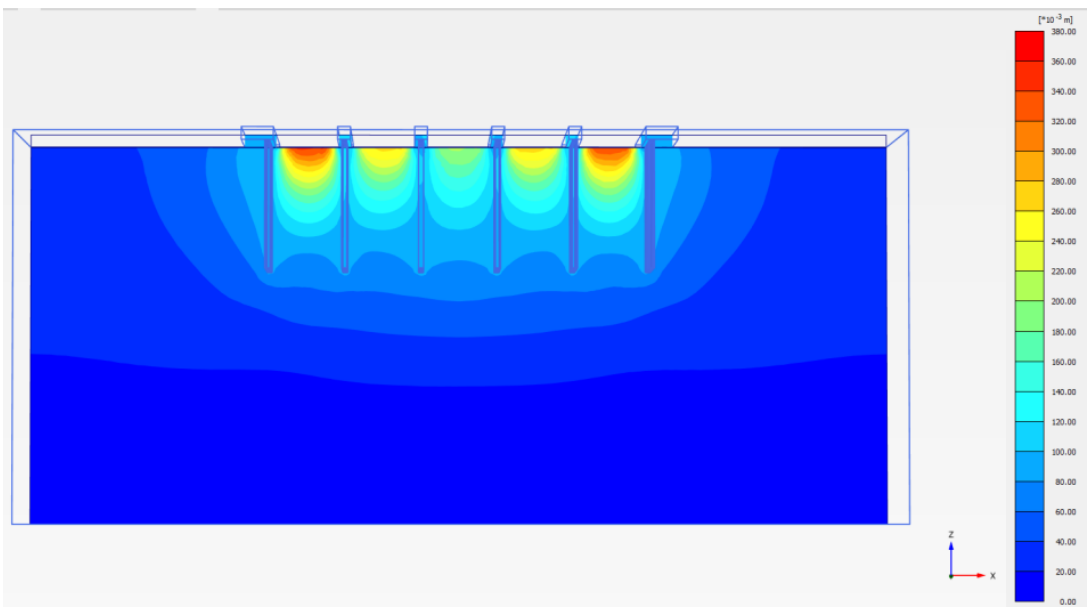


b)

c)
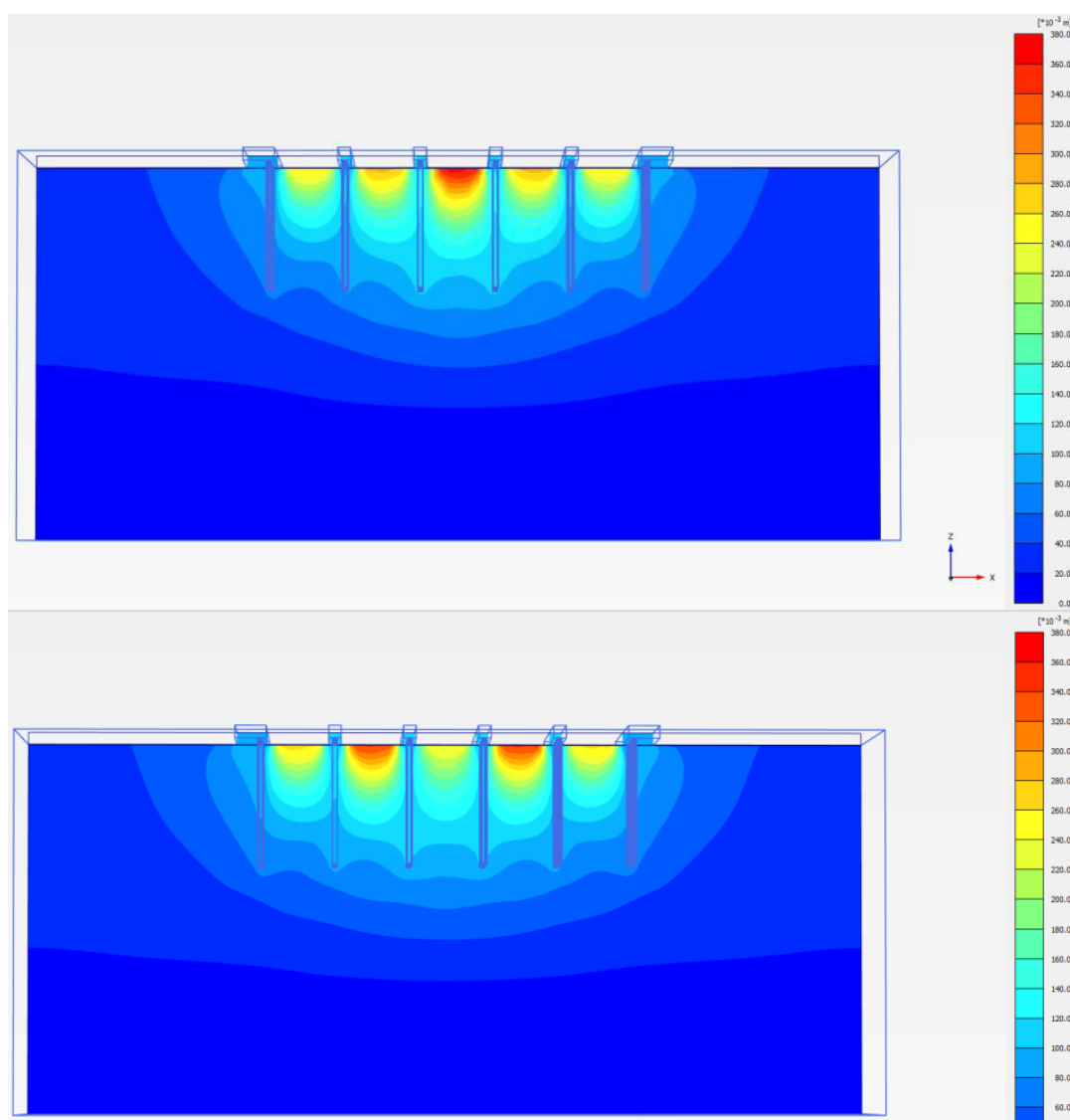

d)
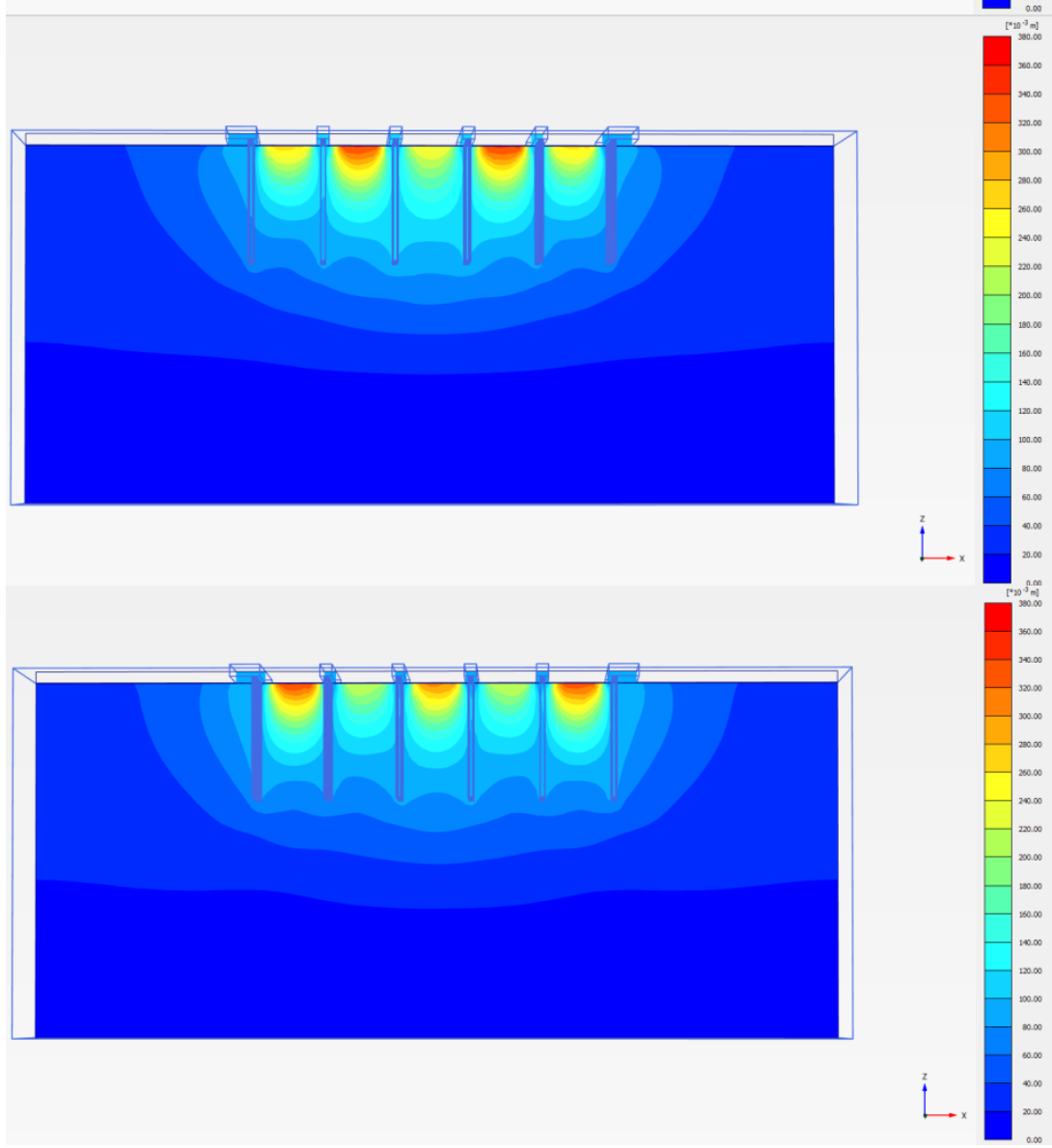

Fig. 3. General movements of pre-stressed soil bed in different flows of pressing: a) P1- No $1+$ No 5 $\rightarrow$ No $2+$ No $4 \rightarrow$ No 3, b) P2 - No $3 \rightarrow$ No $2+$ No $4 \rightarrow$ No $1+$ No 5, c) P3 - No $2+$ No $4 \rightarrow$ No $3 \rightarrow$ No $1+$ No 5 , d) $\mathbf{P} 4$ - No $1+$ No $5 \rightarrow$ No $3 \rightarrow$ No $2+$ No 4

In each case maximum deformations of the pre-stressed soil bed under various flows have been recorded in the bays where pressing is started (Fig. 3). In the case of pressing from the center to the edges (P2), major deformations are concentrated under the central bay and 
develop mainly across the depth reaching a value of $2 \mathrm{~W}$ (Fig. 3b); the most uniform movement of soil bed under the entire area of the tested CSPF has been recorded in cases of P1 (Fig. 3a) and P4 (Fig. 3d). When pressing is carried out from the edges to the center (P1), deformations of soil bed develop mainly across the foundation width; the main deformations across the depth have been recorded at a distance from 1 to $1.5 \mathrm{~W}$ (Fig. 3a). Full attenuation of deformations in each case of pressing flow has been recorded at a depth of up to $4 \mathrm{~W}$, where $\mathrm{W}$ - width of the CSPF bay.

a)

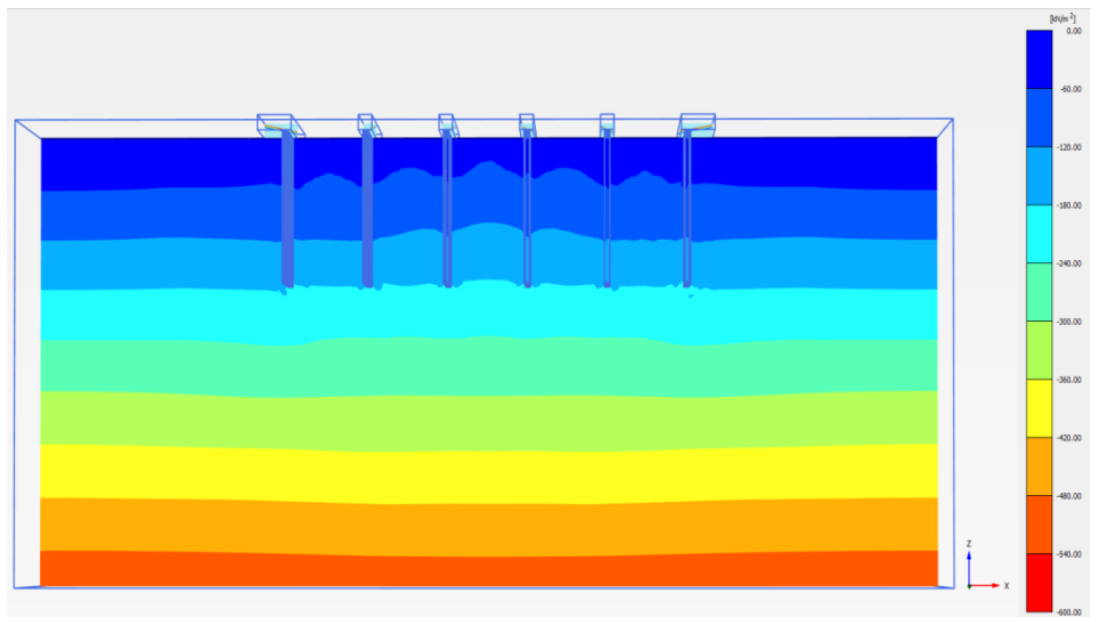

b)
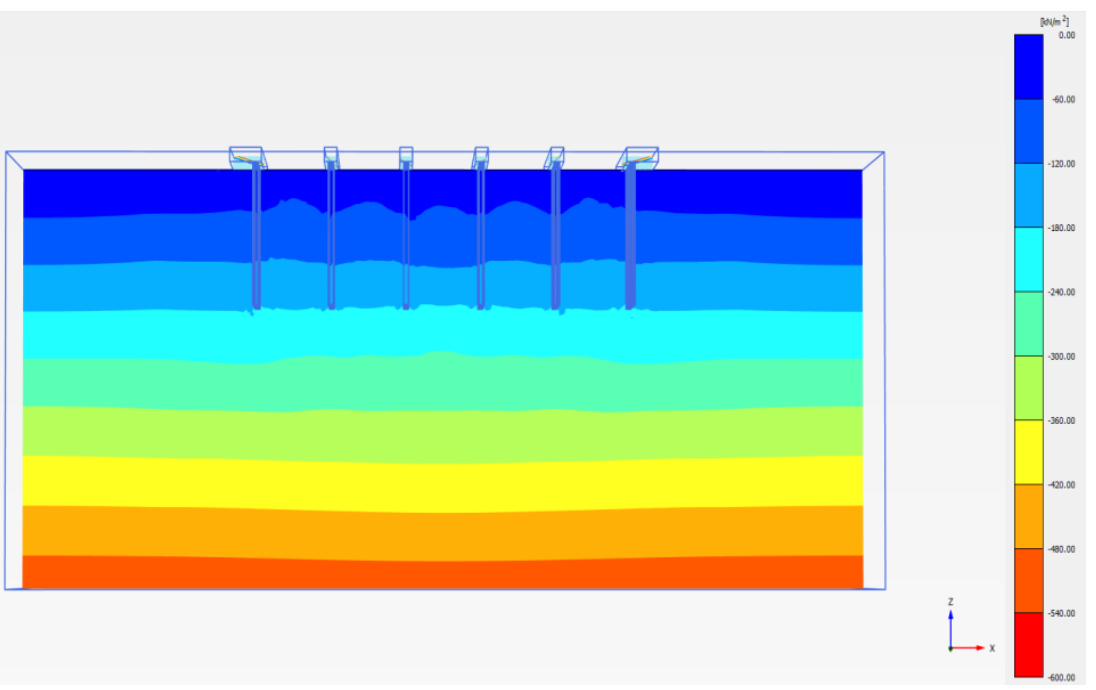
c)

d)
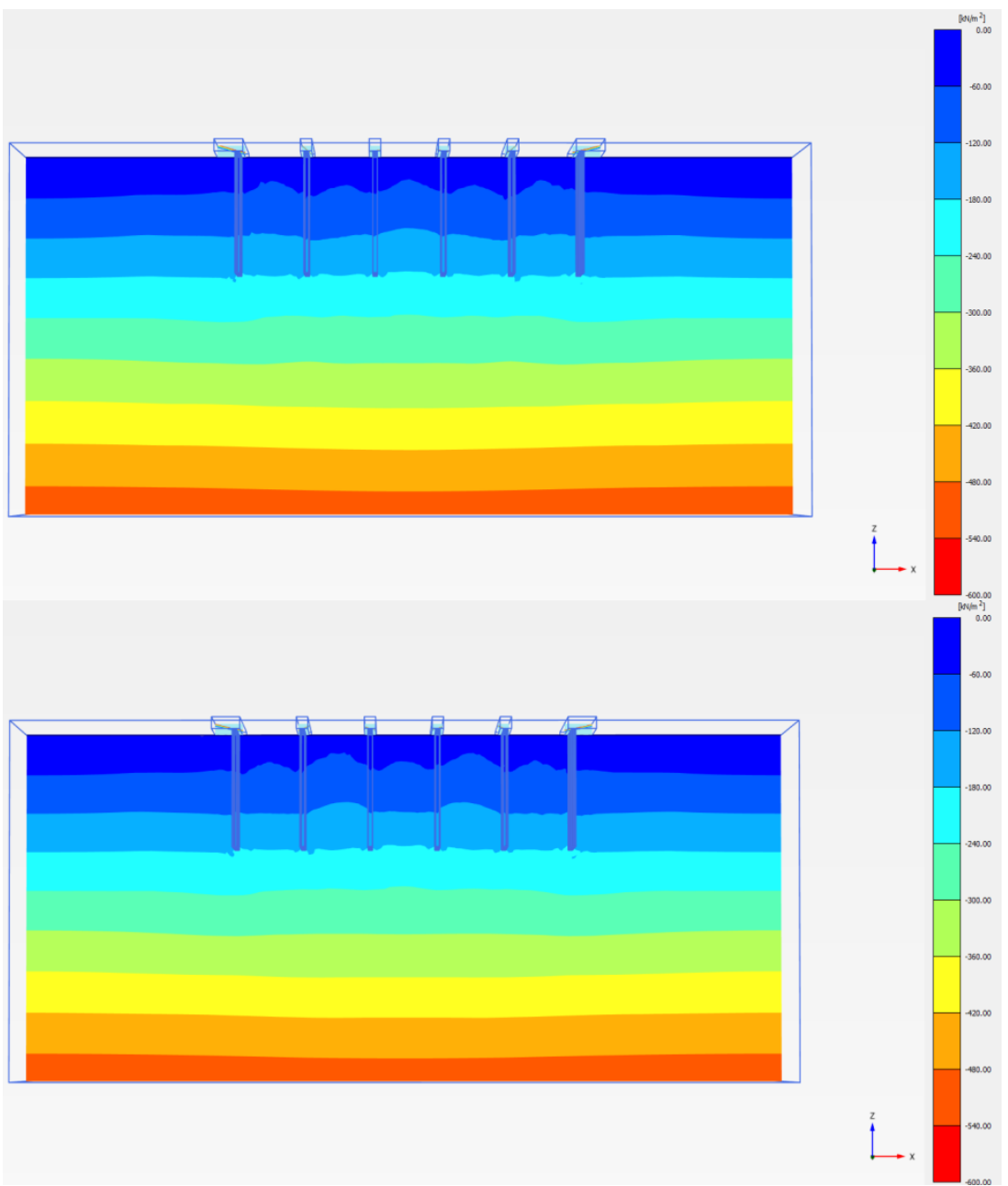

Fig. 4. General stresses of soil bed in different flows of pressing: a) P1- No $1+$ No $5 \rightarrow$ No $2+$ No 4 $\rightarrow$ No 3, b) P2 - No $3 \rightarrow$ No $2+$ No $4 \rightarrow$ No $1+$ No 5, c) P3 - No $2+$ No $4 \rightarrow$ No $3 \rightarrow$ No $1+$ No 5 , d) P4 - No $1+$ No $5 \rightarrow$ No $3 \rightarrow$ No $2+$ No 4 .

In each case maximum stresses of the soil bed under different flows have been recorded in the bays where pressing is stopped (Fig. 4). Thus, in the case of pressing in accordance with P1 (Fig. 4a), the maximum increase of stresses have been observed in the soil located under the central bay of CSPF. When pressing is done from the center to the edges, in accordance with P2 (Fig. 4b) and P3 (Fig. 4c), general stresses increase almost uniformly. The greatest increase of general stresses occurs in the case of pressing in accordance with P4; increase of stresses is up to $200 \%$ and it extends to a depth of up to $1.5 \mathrm{~W}$ (Fig. $4 \mathrm{~d}$ ).

\section{Conclusion}

Thus, the pattern of pressing within one bay with the movement from the center to the edges is the most effective (Pattern P4), making it possible to exert maximum influence on stress-strain state of the foundation soil bed. 


\section{References}

1. N. Kiselev, Y. Pronozin, M. Stepanov, L. Bartolomey and D. Keck, MATEC, 73 (2016)

2. Z. Ter-Martirosyan, V. Telichenko, M. Korolev, Vestnik MGSU, 1, 18-27 (2006)

3. V. Ulickiy, A. Shashkin, K. Shashkin, Geotehnicheskoe soprovozhdenie razvitiya gorodov. (SPb.: "Stroyizdat Severo-Zapad", 2010)

4. M. Rabiei, A. Choobbasti, Geotechnical and Geological Engineering, 34-1, 75-85 (2016)

5. Z. Ter-Martirosyan, Y. Pronozin, M. Stepanov, Soil Mechanics and Foundation Engineering. 49-4, 119-123 (2012)

6. S. Lee, J.-S. Moon, KSCE Journal of Civil Engineering, 21-1, 243-252 (2017)

7. J. Hanisch, R. Katzenbach, G. Konig, In Zusammenarbeit mit dem Arbeitskreis «Pfahle» der Deutschen Gesellschaft fur Geotechnik, (2002)

8. H. Poulos, Geotechnique, 50-2, 95-113 (2001)

9. Y. El-Mossallamy, International Conference on Geotechnical Engineering, Beirut) (2004)

10. B. Lutz, D. Morauf, J. Scheffler, FGeoBAU, 1, 107-115 (2010)

11. N. Gotman, DSc Thesis, (2004)

12. TC18 (2001) Methodes of analysis of piled raft foundations. A report prepared on behalf of technical committee TC18 on piled foundations, international society of soil mechanics and geotechnical engineering

13. R. Melnikov, J. Zazulya, M. Stepanov, O. Ashikhmin, T. Maltseva, Procedia Engineering, 165, 845-852 (2016)

14. G. Pokrovskii, V. Burenkova, Hydrotechnical Construction, 33-2, 80-85 (1999)

15. H. Wang, E. Song, M. Xu, Qinghua daxue xuebao (Ziran kexue ban), 3, 351-354 (2010) 